\title{
PARA REESCREVER A BIOGRAFIA DE MARCEL MAUSS...**
}

\author{
Marcel Fournier
}

Publicado pela editora Fayard, meu livro intitula-se, simplesmente, Marcel Mauss, tendo como capa uma fotografia do jovem Mauss. O editor, contrariamente ao que eu desejava, julgou desnecessário acrescentar um subtítulo, que poderia ter sido "O sábio e o militante" ou, ainda, "O sábio e o cidadão".

Toda atividade de pesquisa ou escrita contém uma grande parte de reflexividade: não se pode escrever uma biografia intelectual de Marcel Mauss sem se questionar a respeito do significado de tal trabalho. Assim, a questão "Como?", substitui a "Por quê?". Como escrever uma biografia de Marcel Mauss? A reflexão que proponho compõese de quatro módulos, quais sejam, 1) a situação da biografia nas ciências sociais, 2) um retrato de

* Conferência proferida durante o XXVI Encontro Anual da Anpocs, de 22 a 26 de outubro de 2002, em Caxambu - MG.
Mauss quando jovem, 3) as dificuldades de escrever uma biografia de Marcel Mauss, e 4) o caráter provisório de toda biografia.

\section{O estatuto da biografia nas ciências sociais}

A biografia, atualmente muito em voga tratando de políticos, escritores, artistas ou vedetes do cinema, permanece, nas ciências sociais, sobretudo na França, um gênero literário secundário. Entre os anglo-saxões, as biografias de pioneiros nas ciências sociais são mais numerosas (Judith Modell, 1983; Jane Howard; Regna Darnell, 1990; James Clifford, 1987 etc.). Sem esquecer, de Steven Lukes, o magistral Durkheim, his life and work, que, infelizmente, nunca foi traduzido para o francês.

Quando o sociólogo aborda a história de sua disciplina, ele privilegia ou a história das idéias e a 
releitura das obras, ou o estudo dos grupos e das instituições. São muitas as releituras de obras: Bruno Karsenti propõe uma "leitura filosófica do fato social total" (1994); Maurice Godelier procura desvendar l'énigme du don etc. Desenvolveram-se, por outro lado, os campos da sociologia do conhecimento, da ciência e do sistema universitário. Devido à auto-reflexividade, as ciências humanas e sociais não puderam escapar ao olhar do sociólogo.

Hoje, é consenso o fato de que, mesmo centrado nas contribuições teóricas de um autor, um estudo deva comportar não somente notas biográficas, como também uma contextualização da obra. Na obra La sociologie de Durkheim, Philippe Steiner (1994) apóia-se, de forma sólida, nos diversos trabalhos recentes sobre estudos durkheinianos, dos quais apresenta uma excelente síntese: "revelação" do ano 1895 e lugar da religião na análise sociológica, fraca homogeneidade da equipe de L'année sociologique e engajamento político dos jovens colaboradores. ${ }^{1}$

Os sociólogos desconfiam, com razão, do que Pierre Bourdieu (1986) chama de "a ilusão biográfica”. Devemos, realmente, sempre reconstruir o contexto, a "superfície social" sobre a qual age o indivíduo, numa pluralidade de campos, a cada momento. O recurso a uma abordagem prosoprográfica permite, como aparece de forma admirável em La république des universitaires, 1870-1940, de Christophe Charle, realizar uma análise sistemática de amostras de biografia de intelectuais ou de professores:

Por meio dessas biografias, encontramos a lógica das estruturas, mas também os dados sociais e culturais que permitem às estruturas evoluir, pois os condicionamentos que traduzem as trajetórias dos locais de formação, dos elos intelectuais ou sociais, indicam quais são as margens do jogo do sistema ou, ao contrário, se ele obriga, para inovar, a recorrer a soluções externas (Charle, 1994, p. 13).

O grande mérito de tal perspectiva é o de "quebrar o modelo unificado e pronto do universitário ideal-típico".
Na quarta capa de Marcel Mauss, pode-se ler: "Meio século após a morte de Marcel Mauss (1872-1950), esta é a primeira biografia do pioneiro das ciências sociais e humanas, cuja vida fomentou tantas aventuras intelectuais na França e no estrangeiro". ${ }^{2}$ Será que se trata apenas de uma biografia? O editor tinha me advertido contra o que poderia ser considerado reducionismo sociológico, e me aconselhou a não usar muitas noções de campo, posição social e habitus. Deve-se sempre ser cauteloso...

Ex-aluno de Pierre Bourdieu, desenvolvi um programa de pesquisa nos campos da sociologia da ciência, da sociologia do sistema universitário e da sociologia dos intelectuais. Marcel Mauss abrange o que poderíamos denominar uma biografia coletiva, pois inclui tanto uma apresentação dos membros da equipe de L'année sociologique, como um estudo das instutuições de ensino superior - Escola Prática de Estudos Superiores, Collège de France - e ainda uma análise do desenvolvimento de disciplinas científicas (história das religiões, antropologia, sociologia). Descrevi Marcel Mauss como um típico intelectual de sua época, que concentra todas as características de seu grupo, por sua trajetória social e escolar e por seus habitus de pesquisador e de militante socialista. Mas será possível identificá-lo dessa maneira quando se pensa, de um lado, em sua juventude e, de outro, em sua maturidade?

\section{Mauss quando jovem}

Toda e qualquer vida, evidentemente, divide-se em períodos. Trata-se dos chamados ciclos da vida - infância, juventude, maturidade e velhice. A biografia de Marcel Mauss compreende quatro partes: "O sobrinho de Durkheim", "O clã totemtabu", "O herdeiro" e "O reconhecimento". A morte de seu pai e de seu avô materno, em 1896, a morte de André Durkheim, em 1915, de Émile Durkheim dois anos depois, a morte de seu melhor amigo, Henri Hubert, em 1927, são datas significativas na vida de Mauss. Mas será que podemos, tendo em vista sua obra, falar em rupturas, e opor o jovem ao velho Mauss, como fez Althus- 
ser para Marx, e Lukes para Durkheim? O jovem Durkheim teria sido mais "materialista", e o velho Durkheim, mais "idealista".

Em um determinado momento, fiquei tentado a descrever Mauss como um jovem rapaz aos moldes de René, de Chateaubriand. O "mal do infinito" que aparece em Le suicide (Durkheim, 1967 [1897]) é o mal do século ao qual se refere Chateaubriand:

Me acusam de ter gostos inconstantes, de não desfrutar sempre da mesma utopia, de estar à mercê de uma imaginação que se apressa para chegar ao fundo de meus prazeres, como se ele fosse vítima de sua duração; me acusam de passar à margem do objetivo que eu posso atingir: infelizmente! procuro apenas um bem desconhecido, cujo instinto me persegue. Será minha culpa, se eu encontro sempre limites, se o que acabou não tem, para mim, nenhum valor? (Chateaubriand, 1992 [1805], p. 155).

René tende para a melancolia, pensa no suicídio, e foge para a América.

Será que Mauss ficou fascinado por esse personagem dândi? Terá ele se identificado com aquele que, fugindo da Europa, partiu para a descoberta tanto da passagem do noroeste como do bom selvagem? "Felizes Selvagens!, exclama René. Oh! que não possa eu gozar da paz que sempre vos acompanha!" (Idem, p. 150). Os Índios que Chateaubriand descobre não são "selvagens" no sentido próprio, são civilizados, mas de uma outra espécie. Com Atala e René, Chateaubriand surge como o primeiro grande poeta de uma "civilização primitiva".

Será que o fato de Mauss ter sido um "solteirão" - casou-se tardiamente em 1934 - nos permite estabelecer uma relação de sua vida com a boêmia e o diletantismo? E o que dizer do doloroso diálogo sobre o finito e o infinito? Durkheim criticava seu sobrinho por sua "inconsciência moral"; ele temia, sobretudo, a "anomia doméstica", deplorando, em Le suicide, a situação - uma "existência medíocre" - na qual se encontra todo celibatário. Estaria Durkheim pensando em Mauss ao escrever essas linhas? Apesar do desespero de seus familiares e amigos, Mauss dificilmente acei- tava se render a novos hábitos e fixar seus limites. Não fosse a presença do tio, o que teria sido dele? Não é fácil responder a essa pergunta. Seguiria os passos de seus pais, como seu irmão caçula Henri, ou teria uma participação ativa na política? Homem de dever, Mauss permaneceu fiel à sua família e a seus amigos, mas também às suas próprias convicções. Jovem, Mauss já se sentia velho, e numa idade mais avançada, manteve-se como um "eterno estudante". Ele, portanto, não mudou muito...

\section{As dificuldades de escrever uma biografia de Marcel Mauss}

Toda biografia integra, implicitamente, uma teoria da ação: o personagem central da história é um ser tanto racional como irracional, guiado por seus interesses e por suas paixões. A inclinação natural, para o autor de uma biografia, é de se apoiar num modelo que "associe uma cronologia ordenada, uma personalidade coerente e estável, ações sem inércia e decisões sem incertezas" (Lévi, 1989, pp. 1325-1326).

Será que poderia ser de outra maneira? Giovanni Lévi acredita que a biografia pode constituir "o lugar ideal para verificar o caráter intersticial e, apesar disso, importante - da liberdade da qual dispõem os agentes" (Idem, p. 1335). Tendo em vista que os sistemas normativos nunca estão isentos de contradições, cabe, portanto, procurar

[...] explicitar as estratégias manipuladoras dos seres sociais em face de uma pluralidade de campos normativos, cuja característica principal é de serem contraditórios uns com relação aos outros. Ao atribuirmos, dessa forma, uma competência aos atores sociais - a capacidade de conhecer essa contradição das normas, a biografia adquire uma nova dimensão: ela permite restituir a espessura e a especificidade da racionalidade dos atores sociais (Cirutti, 1995, p. 25).

Mostrar "aquilo que Mauss foi capaz de fazer", pode ter sido, retomando a expressão de Luc Boltanski, o objetivo de minha biografia intelectual de Marcel Mauss. Ao procurar evidenciar a 
força de um indivíduo, corremos o risco de cair na armadilha que está presente em toda biografia, qual seja, a hagiografia: Mauss-pioneiro das ciências humanas, Mauss-pai fundador da antropologia moderna etc. Contudo, não hesitei em falar do "caráter exemplar da atitude de Mauss".

Para fazer contrapeso a uma abordagem muito racionalista ou voluntarista, podemos tentar mostrar aquilo que o autor não foi capaz de fazer. Mauss poderia certamente ser considerado um caso limite: à margem dos campos intelectual e social, ele teria sido um "fracassado", ao menos no início da carreira. Sua família, sobretudo o tio e a mãe, preocupava-se demasiado com seu modo de vida. O cargo que ele assumira na École Pratique era, segundo sua mãe, uma "armadilha", a tese de doutorado inacabada, o estatuto de celibatário, o ócio, entre outras coisas, eram motivo de inquietação familiar.

Mauss foi alvo de duras críticas, mesmo por parte de alunos que o admiravam: "Faltava tanto talento a esse homem, a ponto de envergonhar. Desejávamos para ele um pouco de habilidade, paciência, aplicação, da menor das qualidades das quais ele se vangloriava e que tanto lhe faziam falta", escreve Roger Caillois (1978, p. 25).

Exemplo modal ou caso limite? A questão central é entender como Mauss - o pequeno judeu de Epinal, sobrinho de Durkheim ${ }^{3}$ e professor universitário de filosofia que não passou pela École normale - tornou-se o "pai da antropologia moderna" (Condominas) e contribuiu de maneira original ao desenvolvimento das ciências humanas. Teria sido bem-sucedido em campos onde outros intelectuais não obtiveram êxito, ou ainda, teria feito melhor do que o próprio Durkheim. ${ }^{4}$

Acredito que Mauss sirva de elo ${ }^{5}$ para aqueles que, hoje, desejam seguir a escola sociológica francesa e, mais do que nunca, estudá-lo é sempre um desafio. O lado "grande sacerdote" de Durkheim continua a incomodar. Mauss, com seu jeito de "mago" que crê no "espírito das coisas", tinha tudo para agradar. Não criamos, há alguns anos, o M.A.U.S.S. - Movimento Anti-utilitarista em Ciências Sociais - como se quiséssemos nos aproveitar de Mauss contra toda sociologia do interesse? Escrever uma biografia de Mauss é, tenho de concordar, inscrever-se nos debates em que a obra de Mauss foi objeto antropológico e sociológico: Cahiers de MAUSS contra Bourdieu, Dumont contra Lévi-Strauss etc.

Como não ser prisioneiro dos conflitos de escolas ou de clãs? A redação de uma biografia intelectual exige a um só tempo uma grande proximidade (familiaridade etc.) ${ }^{6}$ e uma certa distância em relação ao biografado. O fato de a biografia de Durkheim ter sido feita por um inglês e a de Mauss por um canadense leva-nos a pensar que talvez a distância entre o biografado e o biógrafo seja, no caso específico desse tipo de estudo, uma condição pertinente para o pleno desenvolvimento do trabalho, ou seja, estar fora do âmbito universitário francês talvez tenha sido importante, senão crucial, para a análise da vida intelectual desses dois autores.

\section{O caráter provisório de toda biografia}

É possível escrever a vida de um indivíduo? L'idiot de la famille, de Jean-Paul Sartre, permaneceu, com seus três volumes, uma obra inacabada. O biógrafo é confrontado com uma série de problemas, como acesso às fontes e memória de membros da família, ex-alunos e amigos, ou seja, às diversas interpretações das quais a obra do autor foi objeto.

Quando Marcel Mauss (1928) escreveu o necrológio do antropólogo inglês James Frazer, expressou o seguinte desejo: "Uma obra de arte não pode ser outra coisa senão sugestiva. A história de um sábio deve, sim, ser verídica, e deve-se contar tudo". A vida de um indivíduo compreende uma infinidade de fatos e, portanto, é impossível uma biografia exautiva que trace uma idéia completa do biografado. Há lacunas e, por vezes, erros.? "É inevitável", disse-me o editor de meu livro, Olivier Bétourné, no dia da remessa da obra às livrarias. Lamento também não ter podido consultar para a pesquisa de Mauss alguns estudos ou obras como, por exemplo, o primeiro volume da correspondência entre Marc Bloch e Lucien Febvre (1994). Lucien Febvre ironiza: a "igreja de são Durkheim", 
cujos doutores são Bouglé, o "verdadeiro Connet", Simiand e Mauss (Carta de 10 de maio de 1933, pp. 372-373). Também refere-se a Mauss em termos, eu diria, maldosos: "[...] Dumézil é incentivado por todo o grupo de Mauss etc. O espírito corporativo sociológico estaria surgindo no horizonte? Perigo!" (Carta de final de março de 1933, p. 345); "Mauss que lançava com uma voz estrondosa patranhas provocadoras" (Carta de 12 de abril de 1933, p. 353); "Mauss como sempre confuso e estourado" (Carta de 25 ou 26 de abril de 1933, p. 363).

Eu tive acesso, para a realização de meu estudo, ao acervo "Hubert Mauss" dos arquivos do Collège de France, onde se encontra uma parte importante da correspondência recebida por Marcel Mauss e também, quando conservada por ele, a cópia em carbono das cartas datilografadas que ele enviou. ${ }^{8}$ Esse acervo compreende, outrossim, toda a correspondência entre Durkheim e Mauss. Trata-se de uma rica fonte de pesquisa que eu, evidentemente, explorei bastante, mas algumas cartas muito interessantes não foram citadas. A seguir apresento trechos dessa correspondência.

Bouglé nomeado, Richard coroado(!), Lévy, professor titular, você e Hubert na École. É um bom ano para L'Année. Sobra apenas este Pobre Pequeno Falcão (carta de Emile Durkheim a Marcel Mauss, s.d. [novembro 1901])

Em janeiro de 1915, Mauss pede a seu tio que lhe envie cinco livros de Shakespeare e um dicionário inglês. Em dezembro de 1915, quando Durkheim retoma suas aulas, escreve: "É extenuante. Meu fim como professor está próximo" (carta de Émile Durkheim a Marcel Mauss, $1^{\circ}$ de dezembro de 1915). "Retomei minhas aulas. Só Deus sabe o quanto me são indiferentes! Este é um trabalho que não pretendo continuar a fazer por muito tempo, a menos que a guerra nos arruíne. Não o suporto" (carta de Émile Durkheim a Marcel Mauss, 6 de dezembro de 1915). Em março de 1916, quando Durkheim está muito doente, escreve:

Tenho contra mim, como previa, a infeliz faculdade que me permite remoer a mesma idéia, pensar sobre a mesma coisa, dia e noite, durante cinqüenta anos se for necessário. Para escapar a uma obsessão, só tenho a atividade e o trabalho. Enquanto o trabalho me sustenta pelo interesse, pela vida que ele desperta em mim, tudo bem. Do contrário, há a queda, e tenho que lutar contra o abatimento, isto é, contra as imagens que se acapararam de mim. [...] $\mathrm{Na}$ medida em que se pode prever o futuro, a melancolia será o meu modo de vida. Mas possuo, naturalmente, uma tendência suficiente [...]. Não sei se algum dia rirei muito, mas posso dispensar o riso. E minha vida parece que está se orientando nesse sentido. Você não acreditaria que alegria dá essa sensação de desprendimento devido ao fato de não se ter mais interesse temporal (carta de Émile Durkheim a Marcel Mauss, 19 de março de 1916).

Meu caro Marcel, a guerra não te curou de seu dogmatismo. Você é infinitamente mais dogmático que eu. Eis, agora, uma teoria sobre os estudantes americanos! Rogo-te, cuide dessa tendência que parece se desenvolver em você. Não somos obrigados a ter uma opinião sobre [ilegível] (carta de Émile Durkheim a Marcel Mauss, 19 de abril de 1916).

Toda a correspondência entre Durkheim e Mauss - mais de quinhentas cartas - foi publicada pela PUF (em colaboração com Philippe Besnard). Tal documentação servirá a um próximo livro, Durkheim, Mauss e Cia.

Quem fala em biografia, fala em inquérito. Procuramos rastros deixados por um homem na sua vida, ou na vida de outros; reunimos "provas" e interrogamos "informantes". Meu encontro com os "informantes" quando da elaboração de Mauss foi apaixonante. Acredito que as entrevistas com Louis Dumont, Denise Paulme, Germaine Tillion, Jean Margot-Duclote e André-Georges Haudricourt merecem ser publicadas integralmente. A maioria deles foi muito acolhedora; alguns mais discretos, outros menos cooperativos. Doente, Michel Leiris só me dedicou uma breve conversa telefônica.

Quanto a Claude Lévi-Strauss, desde o nosso primeiro encontro, ele deixou muito claro que não queria ser considerado um "informante-chave". "Não fui aluno de Mauss, não o conheci", assim disse-me à época. No entanto, seu depoimento era crucial, dada sua correspondência com Mauss entre 1936 e 1944, timbradas no Rio de Janeiro e em Nova York. Uma das cartas, datada de 
2 de outubro de 1944, é de grande interesse, pois Lévi-Strauss comenta sua pesquisa sobre o sistema de parentesco, questionando qual poderia ser o título de sua obra: "Proibição do incesto", "Aliança e parentesco" ou "Introdução à teoria geral dos sistemas de parentesco"? Como explicar essa recusa? Seria ela um reflexo de defesa ou uma posição teórica? É bem verdade que o conhecimento da vida de um autor nem sempre permite uma melhor compreensão de sua obra. Será,então, que não valeria mais a pena deixar os textos falarem por si só?

A realização de um estudo biográfico necessita da colaboração daqueles que chamamos de partes legítimas e dos que controlam o acesso e o uso dos arquivos familiares. Muito gentis, os membros da família Mauss (sobrinhos Pierre e François e Marie) sempre se mostraram dispostos a me ajudar, respondendo às minhas perguntas ou fornecendo os documentos solicitados. Recentemente, Pierre Mauss enviou-me a cópia de uma carta de introdução de Jean Jaurès a Mauss, a qual, segundo ele acreditava, talvez fosse "útil aos escritos políticos". "Peço aos meus amigos russos que consideram que o Sr. Mauss me representa plenamente em tudo o que diz respeito aos interesses do jornal l'Humanité, e de confiar nele assim como confiariam em mim". Jaurès escreveu essa carta no dia 18 de julho de 1906, quando seu amigo Mauss partia "numa missão científica" na Rússia. Tive de fazer escolhas: o que não pude utilizar para a biografia de Mauss, eu o fiz para a edição de seus Escritos políticos.

Era evidente que, antes da publicação da biografia de Mauss, eu submeteria o manuscrito à apreciação de sua família. Tratava-se de um compromisso implícito, o que considerei, sob alguns aspectos, uma vantagem, pois permite fazer, quando necessário, correções de datas, eventos ou, até mesmo, de possíveis interpretações equivocadas. Mas quem não teme as reações da família? Não alterei substancialmente meu texto, mas tive de respeitar algumas "suscetibilidades" da família Mauss, que se referiam, evidentemente, à sua vida privada: relacionamentos amorosos, questões de dinheiro, várias histórias familiares. Por exemplo, há muitas alusões no texto à generosidade de Mauss
- doações ou empréstimos ao Partido, ao movimento cooperativo ou a amigos (Beuchat, Fauconnet) -, mas nunca mencionei o montante dos valores em causa. Além disso, e eu me arrependo, não forneci nenhuma informação a propósito da herança (imóveis, ações etc.) que Marcel Mauss deixou a seu irmão Henri.

Outra questão delicada diz respeito ao relacionamento entre Marcel Mauss e Marcel Déat, ambos professores titulares de filosofia, durkhenianos, soldados durante a Primeira Guerra Mundial e militantes do movimento socialista. Apesar de Mauss não ter encontrado Déat na década de 1930, nem compartilhado com ele a trajetória que o conduziu da alienação à colaboração, ele conservou essa amizade até a primavera de 1930: "Num primeiro momento vi poucos artigos seus que eu não teria aprovado" (Carta de Mauss a Marcel Déat, 21 de abril de 1939).? Durante a ocupação, Mauss teria intervindo junto a Déat e vários membros do governo, provavelmente Jérôme Carcopino, para obter a liberação de um pesquisador do Musée de l'Homme, Anatole Lewitszky, e de sua amiga, Yvonne Oddon, membros de uma das primeiras fileiras da Resistência.

Durante todo o período da ocupação, Mauss permaneceu em Paris devido a problemas de saúde de sua mulher. Teria sido ele protegido por suas relações e notoriedade? Possivelmente sim, já que alguns alemães o estimavam muito, além de ter sido companheiro ou colega de pessoas, como Jérôme Carcopino, Max Bonnafous, Hubert Lagardelle e Marcel Déat, que ocupavam funções administrativas ou políticas durante a ocupação. No entanto, não há provas disso, mas apenas o fato de inserir no texto as ligações entre Mauss e Déat pode, evidentemente, causar polêmica ou irritação, mas tive de fazê-lo para permitir uma melhor compreensão daquilo que os opôs.

\section{A descoberta de um novo informante}

O que fazer quando, finalizado o livro, ficamos sabendo da existência de um informante que dávamos por morto? A descoberta de um "novo" informante obrigaria a reescrever a biografia? Por 
ocasião do colóquio sobre as regras do método sociológico que ocorreu em Bordeaux, Pierre Mauss me pôs em contato com Pierre Métais,$^{10}$ antigo aluno de Mauss, advertindo-me sobre sua idade avançada e seus problemas de saúde.

Métais aguardava-me em pé, vestido com um robe e segurando uma bengala quando cheguei à sua casa na periferia de Bordeaux. A entrevista foi extremamente cordial. Métais divertia-se ao me contar, em quebequense, com o uso de algumas expressões mais familiares e regionais do Québec, histórias de sua vida, como, por exemplo, o período em que fora professor na Nova Caledônia, onde convivera com missionários canadenses franceses. Disse-me que apesar de não ter podido voltar a esse país, nunca mais o esqueceu; havia se tornado "incivilizado, um verdadeiro Kanak". Filho de camponeses, Métais parecia um lobo solitário. Permaneceu um marginal não só em relação à sociedade francesa, mas também à vida acadêmica, mesmo quando ocupara, a partir de 1954, a cadeira de etnologia em Bordeaux. Em seus cursos, a influência do mestre era evidente. Diziam de Métais o que tinham dito de Mauss: "O senhor não quis nos ensinar nada mais do que aprender a ver e a sentir. [...] O senhor recusava o magistral e o dogmático".

Durante nossa entrevista, que durou mais de uma hora, Métais contou-me sobre seu percurso intelectual e a descoberta da etnologia: "Não sabia o que era etnologia, mas eu a praticava o tempo todo". Seus encontros marcantes tinham ocorrido em meados da década de 1930, com Lucien LévyBruhl, Paul Rivet e, evidentemente, Marcel Mauss.

Mauss me disse para ler o livro de Morgan sobre os Algonquins. Ele me fez ler tudo o que havia sido escrito sobre os índios do Canadá e dos Estados Unidos. [...] Com Mauss, procurávamos o que era primitivo. Com Mauss, explorávamos as instituições elementares da religião; estudávamos também as estruturas de parentesco nas sociedades primitivas.

Mauss sempre the dera o seguinte conselho: "Nada de teoria. Ele observa e você descreve". "Era um homem de sensações: tinha de tocar e ver". Métais conhecera bem Marcel, primeiro como aluno e, em seguida, como amigo. Ele foi um dos que visitou regularmente o "caro mestre" durante os anos de guerra e no pós-guerra, tendo até mesmo morado por algum tempo em seu apartamento no boulevard Jourdan. Eu nunca havia ouvido antes a expressão carinhosa pela qual Métais se referia ao amigo: "compadre Mauss". Quando falava dele, Métais não conseguia esconder suas emoções: "[Ao final da guerra de 1939-1945], Mauss tomava a sopa popular. Relembrando isso, eu choro de pena". Quando, ao final da entrevista, eu pedi a Pierre Métais que me falasse a respeito dos funerais de Mauss, ele me respondeu: "Foi triste. Éramos apenas cinco ou seis". Em seguida, levantou sua bengala em posição de ataque e, com a fisionomia enrijecida pela raiva, acrescentou: "Não lhe direi quem estava lá, pois ficaria sabendo quem não estava".

O Compadre Mauss! Incrível Mauss!

\section{NOTAS}

1 Podemos, no entanto, lastimar alguns esquecimentos: por exemplo, não existe nenhuma referência ao engajamento político de Durkheim durante a Primeira Guerra; não se fala do fato de Durkheim ser judeu ou de seu relacionamento com o judaísmo, senão que ele "é o quarto filho de uma família judia tradicional, de condição modesta”; sua ambição de entrar no Collège de France nunca foi mencionada.

2 André-Marcel D'Ans, Les Nouvelles littéraires; Georges Balandier, Le Monde; Xavier Blaisel, Anthropologie et sociétés.

3 Quando ele apresentou a candidatura de Marcel Mauss em 1930 ao Collège de France, Charles Andler ousou dizer que Mauss era "melhor aparelhado" que seu tio. Suas qualidades são: um "vigor de trabalho pouco comum, uma abnegação, uma carga imensa de esperança”, um conhecimento de várias línguas antigas, uma formação completa de etnógrafo, uma competência de museógrafo, o cuidado de "revisar constantemente as mesmas regras de método". Andler concluía: sua obra é "imponente, prolongada por importantes promessas" (Charles Andler, "Proposta para a criação de uma cadeira de sociologia no Collège de France", exposição feita no 
dia 15 de junho de 1930, assembléia de professores,1925-1934, Arquivos do Collège de France, G 1113, p. 176). Ver Marcel Fournier (1996).

4 "Pode-se [constatavam Pierre Bourdieu e Jean-Claude Passeron, 1967, p. 166] reconhecer sua ascendência durkheiniana somente por meio de seus respeitáveis parentes - o primo inglês Radcliffe-Brown ou o executor testamentário, Marcel Mauss, cuja posição de assistente glorioso salvou do ridículo [...].

5 Elizabeth Roudinesco (1993).

6 Uma familiaridade muito grande pode, evidentemente, conduzir à cumplicidade e à complacência. Em face das críticas das quais foram objeto Fernand Braudel, Pierre Daix não teve outra escolha senão tomar partido em favor de seu amigo e lhe dar razão frente a e contra todos (Daix, 1995).

7 Por exemplo: o esquecimento na bibliografia de um texto de Mauss "Wett, Wedding", publicado na Revue Historique du Droit Français, 1927 (em Études durkheimiennes, outubro de 1984); há um erro: o G de (Georges) Blondel transformou-se, durante a revisão final, num (Charles); uma mesma citação se encontra nas pp. 439 e 673; alguns erros no índice.

8 Pode-se dificilmente fazer o inventário completo das cartas recebidas ou enviadas por Mauss. A senhora Françoise Morin, professora de etnologia na Universidade de Toulouse-Le Mirail e ex-aluna de Roger Bastide me transmitiu recentemente a cópia de duas cartas de Marcel Mauss a Roger Bastide datadas de 3 de novembro de 1936 e de 5 de abril de 1937. A primeira carta permitia conhecer aquilo que Mauss pensava sobre o trabalho de Max Weber: «Recebi o seu pequeno livro. [...] Sua introdução me pareceu muito filosófica. Acrescento que um desses que o senhor aprecia particularmente, Max Weber, é um daqueles com os quais Durkheim, Hubert e eu mesma menos concordamos. Naturalmente, quando ele se contentava de copiar, o que ele fez durante a guerra - época durante a qual tudo era desculpável -, tínhamos razões para nos irritarmos. Mas ele se limitou a emitir opiniões, das quais várias são sugestivas e, algumas, válidas, mas nenhuma, salvo exceção, foi provada. Esta consideração para Max Weber é também uma das coisas que me incomodam no grande volume do meu primo Raymond Aron" (Carta de Marcel Mauss a Roger Bastide, 3 de novembro de 1936).
9 Fundo Hubert-Mauss, Arquivos do Collège de France.

10 Cf. Christian Meriot (1995, p. 8).

\section{BIBLIOGRAFIA}

BLOCH, Marc \& FEBVRE, Lucien. (1994), Correspondance (tome 1, La naissance des Annales, 1928-1933). Paris, Fayard (edição preparada e apresentada por Bertrand Muller).

BOURDIEU, Pierre. (1986), "L'illusion biographique". Actes de la recherche en sciences sociales, 62 (63): 69-72, jun.

BOURDIEU, Pierre \& PASSERON, Jean-Claude. (1967), "Sociology and philosophy in France since 1945: death and resurrection of a philosophy without subject". Social Research, 34 (1), set.

CAILLOIS, Roger. (1978), Rencontres. Paris, PUF.

CHATEAUBRIAND, René de. (1992 [1805]), AtalaRené. Paris, Flammarion.

CHARLE, Christophe. (1994), La république des universitaires, 1870-1940. Paris, Seuil.

CIRUTTI, Simona. (1995), "Normes et pratiques", in B. Lepetit (org.), Les formes de l' experience: une autre bistoire soliale, Patis, Albin Michel, pp. 127-145.

CLIFFORD, James. (1987), Maurice Leenhardt. Personne et mythe en Nouvelle-Calédonie. Paris, Jean Michel Place.

DAIX, Pierre. (1995), Braudel. Paris, Flammarion.

DARNELL, Regna. (1990). Edward Sapir. Berkeley, University of California Press.

DURKHEIM, Émile. (1964 [1897]), Le suicide, étude sociologie. Paris, Presses Universitaires de France.

FOURNIER, Marcel. (1994), Marcel Mauss. Paris, Fayard.

. (1996), "L' élection de Mancel Mauss au Collège de France". Gèneses, 22: 160166, mar. 
GODELIER, Maurice. (1996), L'énigme du don. Paris, Fayard.

HOWARD, Jane. (1984), Margaret Mead, a life. Nova York, Simon and Schuster.

KARSENTI, Bruno. (1994), Marcel Mauss, le fait social total. Paris, PUF (col. Philosophies).

LÉVI, Giovanni. (1989), "Les usages de la biographie", Annales ESC, set.-dez.

LUKES, Steven. (1985), Durkheim, his life and work. Stanford, Stanford University Press.

MERIOT, Christian. (1995), "Homenagens a Pierre Métais", in L'Ethnologie à Bordeaux: hommage à Pierre Métais, Bordeaux, Universidade de Bordeaux.

MODELL, Judith. (1983), Ruth Benedict: patterns of a life. University of Pennsylvania Press.

ROUDINESCO, Elizabeth. (1993), Jacques Lacan, esquisse d' une rue, histoire d' un sustème de pensée. Paris, Fayard.

SARTRE, Jean-Paul. (1971). L'idiot de la famille. Paris, Gallimard.

STEINER, Philippe. (1994), La sociologie de Durkheim. Paris, La Découverte. 


\section{PARA REESCREVER A BIOGRA-} FIA DE MARCEL MAUSS

\author{
Marcel Fournier
}

Palavras-chave

Marcel Mauss; Biografia; Metodologia.

Existe um "mistério Mauss": a questão é entender como Mauss-o pequeno judeu de Épinal, Mauss-o professor universitário de filosofia que não passou pela École Normale, Mauss- o sobrinho sempre à sombra de seu tio Émile Durkheim, Mauss-o intelectual e o militante, tornou-se o "pai da antropologia moderna" contribuindo de maneira original ao desenvolvimento das ciências humanas. Após a publicação da primeira biografia de Marcel Mauss (Paris, Fayard), da edição de seus Escritos políticos (Écrits politiques, Paris, Fayard) e de sua correspondência com Durkheim (Paris, PUF), proponho uma reflexão sob dois aspectos: 1) a situação da biografia nas ciências sociais; e 2) as dificuldades em escrever uma biografia de Marcel Mauss (1872-1950). Essas dificuldades - inúmeras - são de ordem metodológica (coleta e interpretação de dados) e teórica (teoria da ação). A questão que o biógrafo levanta, no início de suas pesquisas, - "Fracasso ou êxito de uma vida?" - transformase, ao final do trabalho, na seguinte pergunta: "Fracasso ou êxito de uma biografia?".

\section{REWRITING THE BIOGRAPHY OF MARCEL MAUSS}

\author{
Marcel Fournier
}

\section{Key words}

Marcel Mauss; Biography; Methodology.

There's a "Mauss mystery:" the question is to understand how Mauss-the tiny Jew of Épinal, Mauss-the Philosophy professor who didn't study at the École Normale, Mauss-the nephew always in the shade of his uncle, Émile Durkheim, Mauss-the intellectual and the militant, became the "father of modern anthropology," contributing in a distinct way to the development of the human sciences. After the publication of the first biography of Marcel Mauss ( $\mathrm{Pa}$ ris, Fayard), the publication of his Political writings (Écrits politiques, Paris, Fayard), and the publication of his correspondence with Durkheim (Paris, PUF), I propose a reflexion on two aspects: 1) the situation of biography in the social sciences; and 2) the difficulties of writing a biography of Marcel Mauss (1872-1950). The question raised by the biographer in the beginning of his researches, "Failure or Success of a Life?" turns, in the end of the paper, into another question: "Failure or Success of a Biography?"

\section{POUR RÉÉCRIRE LA BIOGRA-} PHIE DE MARCEL MAUSS

\author{
Marcel Fournier
}

\section{Mots-clés}

Marcel Mauss; Biographie; Méthodologie

Il y a un "mystère Mauss": comment Mauss-le petit juif d'Épinal, Mauss l'agrégé de philosophie qui n'a pas fait l'École normale, Mauss-le neveu à l'ombre de son oncle Émile Durkheim, Mauss-le savant et le militant, est devenu le "père de l'anthropologie moderne", fournissant une contribution des plus originales au développement des sciences humaines? À la suite de la publication de la première biographie de Marcel Mauss (Paris, Fayard), de l'édition des Écrits politiques de Marcel Mauss (Paris, Fayard) et de la correspondance entre Durkheim et Mauss (Paris, PUF), je vous propose une réflexion à deux volets : 1) le statut de la biographie en sciences sociales; et 2) les difficultés d'écrire une biographie de Marcel Mauss (18721950). Ces difficultés, nombreuses, sont d'ordre méthodologique (collecte et interprétation des données) et théorique (théorie de l'action). La question "Échec ou réussite d'une vie ?" que se pose le biographe au début de sa recherche devient, une fois son travail terminé, "Échec ou réussite d'une biographie?". 